\title{
Electrical Technologies for Grid Integration of Ocean Wave Power into the UK National Grid
}

\author{
Tarek Ahmed ${ }^{\dagger}$ \\ ${ }^{\dagger}$ Dept. of Renewable Energy, University of Exeter, Cornwall Campus, United Kingdom
}

\begin{abstract}
In this paper, multiple offshore wave energy converters with different output characteristics are connected to one power distribution substation. The connection between the power take-off of the different wave energy converters and the electrical power transmission system is presented in order to investigate whether multiple wave energy converters can augment energy yield and improve network integration capabilities. Moreover, the model of an array of wave energy converters is developed with the goal of analyzing the effects of the offshore wave farm on the electrical network to which it is connected. It is also developed to ensure that the electricity generated by the array is sufficiently controllable, and of a quality that can be integrate into the electricity supply network without unduly increasing the cost of connection, production or delivery.
\end{abstract}

Key Words: Electrical Power Generation Systems, Induction and PM Generator, Inverter, Wave Energy

\section{INTRODUCTION}

The ever increasing demand on the fossil fuel reserve not only has a significant effect on the environment through climate change but it also leads to depletion of the supply and hence higher fuel prices. More clean, affordable and sustainable forms of energy, mainly renewable energy are needed to replace conventional energy sources for a secure future. Renewable energy has become attractive to many countries as its sources are available and friendly to the environment. Moreover it plays a major role in the economy as it creates more jobs and, most importantly, is a secure and limitless supply of energy [1].

In the last five years, ocean energy has received considerable attention and there has been a resurgence of interest in wave energy, especially in Europe. Wave energy can be extracted and converted into electricity by wave energy devices deployed either on the shoreline or in deeper waters offshore [2], [3].

Wave energy in the UK has the potential to generate up to one sixth of the UK's electricity consumption. The potential for the integration of wave power into the electric power grid is high, but as in the offshore wind context, the degree of penetration will depend on the adverse impacts it might have on the power network and the technology available to mitigate these impacts [4]-[8]. Most of the lessons learned from the grid interface technology for wind farms can be readily applied to wave farms [9]. However, the achievement of a cost-effective technology is the main concern for commercial development of wave energy converters (WECs). Research

\footnotetext{
Manuscript received Aug. 17, 2009; revised Apr. 7, 2010

† Corresponding Author: tarekahmed@ieee.org

Tel:+44(0)1326254133, Fax:+44(0)1326370450, Exeter University

Dept. of Renewable Energy, University of Exeter, United Kingdom
}

efforts need to be focused in this direction to extract electrical energy from sea waves in a commercially and technologically acceptable manner. Due to the introduction of new grid codes for renewable energy sources a number of issues have to be solved and need to be considered, such as the control applied by the generator and power conditioning system for increased production, low voltage harmonics and power fluctuations [10]-[12].

In this paper, an array of different offshore wave energy conversion devices using a power generation system designed to create an efficient facility for grid power integration is presented. The power generation system consists of a $10 \mathrm{mile}$ sub-sea cable and a distribution unit connected to four wave energy devices. This paper should be of assistance in finding electrical connection configurations for WECs. The results from this model will allow for the analysis of simple wave farm set-ups. Arrays can then be investigated to reduce power output fluctuations and improve the whole power generation efficiency to take advantage of arrays.

\section{PROPOSED SYSTEM UNDER STUDY}

The southwest region of the UK is currently experiencing significant activity in the area of wave energy development to create a major grid-connected project off the north coast of Cornwall. As can be seen in Fig. 1, the grid connection will be made via the power distribution substation at Hayle. When operating at $11 \mathrm{kV}$, the wave power plant is capable of delivering $16 \mathrm{MW}$ of power. One of the objectives, in addition to assisting in the commercial advancement of wave generation technologies, is to evaluate the smoothing effect which appears when the output of the different WECs in the farm are added. Because energy production follows the time variations of the 


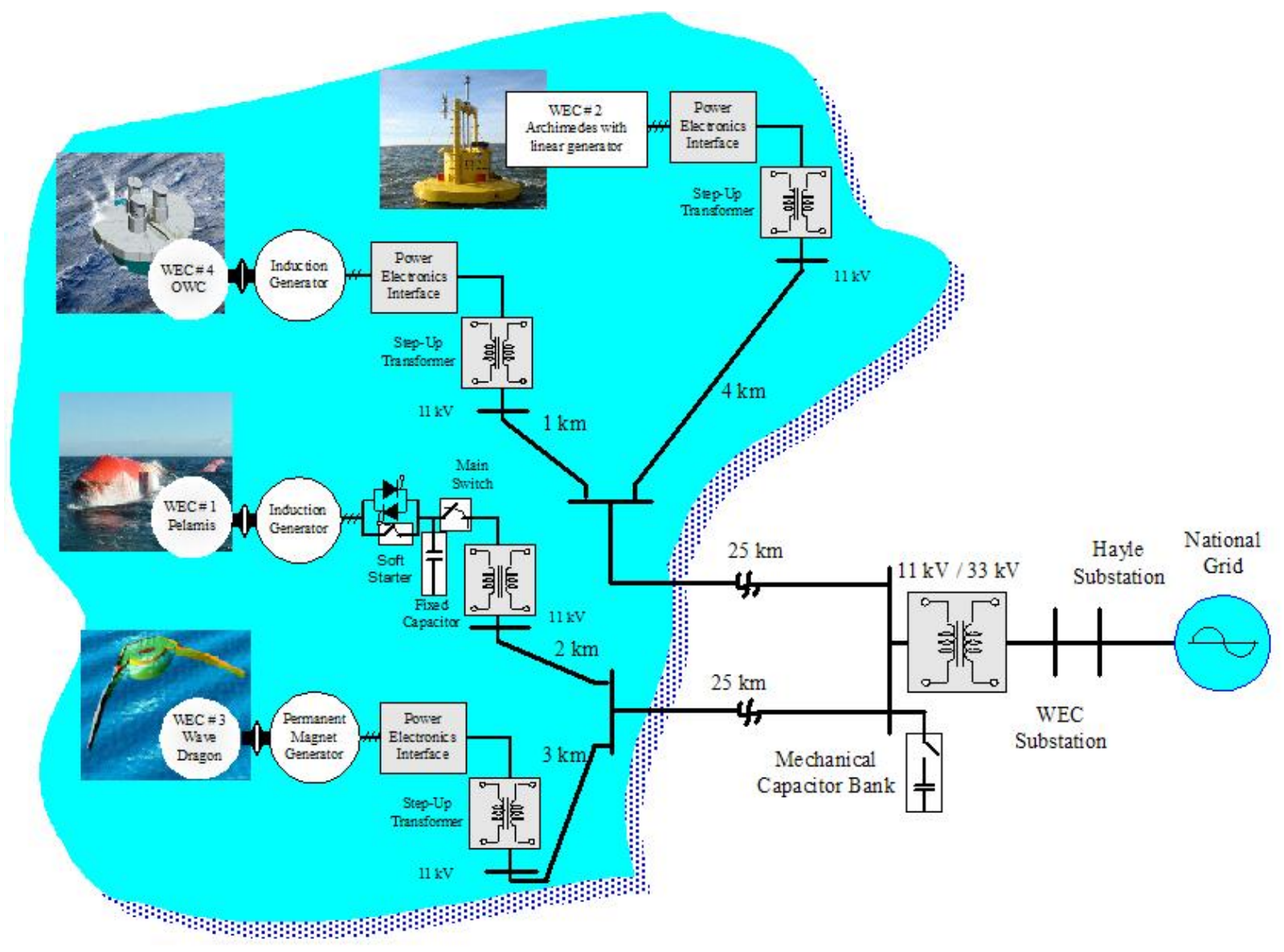

Fig. 1. Single-line diagram of the commercial development for grid integration of multi ocean wave energy conversion devices.

resources, the power output of each system can vary widely and an important energy storage capacity, acting as a buffer, is necessary. Adding the power produced by each system significantly reduces the time standard deviation of the power output. This leads to lower costs for storage and to a more constant method of energy production.

The wave power plant is connected to the power distribution substation at the $33 \mathrm{kV}$ level as shown in Fig. 1. The system initially operates at $11 \mathrm{kV}$ and therefore the substation comprises an $11 \mathrm{kV} / 33 \mathrm{kV}$ transformer with associated switchgear. The $11 / 33 \mathrm{kV}$ onshore substation transformer is rated at 20MVA with a typical nominal turns ratio of $33 / 11$ and a nominal impedance of $10 \%$. Power factor correction equipment is installed at the substation to ensure delivery to the grid within predetermined specifications.

The wave energy system has been modeled in MATLAB/SIMULINK. The model is made up of four offshore WECs. Each unit, rated at $4 \mathrm{MW}$, is connected through an $11 \mathrm{kV}$ bus via $25 \mathrm{~km}$ of 6 -core $300 \mathrm{~mm}^{2}$ cable. They are initially operated as two independent circuits that connect two WECs. Additional cables of $1 \mathrm{~km}-4 \mathrm{~km}$ are also required. Stepup transformers on the WECs are also modeled to compute accurately the voltage rise at the terminals of the WECs units. The electrical parameters of the 6 -core $300 \mathrm{~mm}^{2}$ cable used in the system modeling are $R=0.0745 \Omega / \mathrm{km}, L=0.34155 \mathrm{mH} / \mathrm{km}$ and $C=0.208 \mu \mathrm{F} / \mathrm{km}$.

\section{REACTIVE POWER CONTROL OF A WAVE POWER PLANT}

The reactive power control of a wave power plant will have a significant impact on the voltage level of the WECs. Therefore, reactive power control is required to keep the voltage level with its limits. It also reduces the rms currents in order to improve the wave power plant efficiency and keep the terminal voltages within acceptable limits. In order to control the reactive power of a wave power plant within its limits, some means of reactive power control based on a reactive power compensation unit installed onshore and/or an offshore WEC power factor control are utilized. In Fig. 1, an onshore reactive power compensation unit is installed to absorb or generate additional reactive power and thus control the amount transferred to the power distribution substation.

At the onshore $11 \mathrm{KV} / 33 \mathrm{KV}$ substation, minimal reactive power interchange must be provided while WEC power factor control is constrained to a controlled value between 0.98 (inductive) and unity.

Given the significant variance between the reactive power and the active power, some form of dynamic reactive power control will be required on an $11 \mathrm{kV}$ substation to maintain the power-factor at the $33 \mathrm{kV}$ point of connection. 


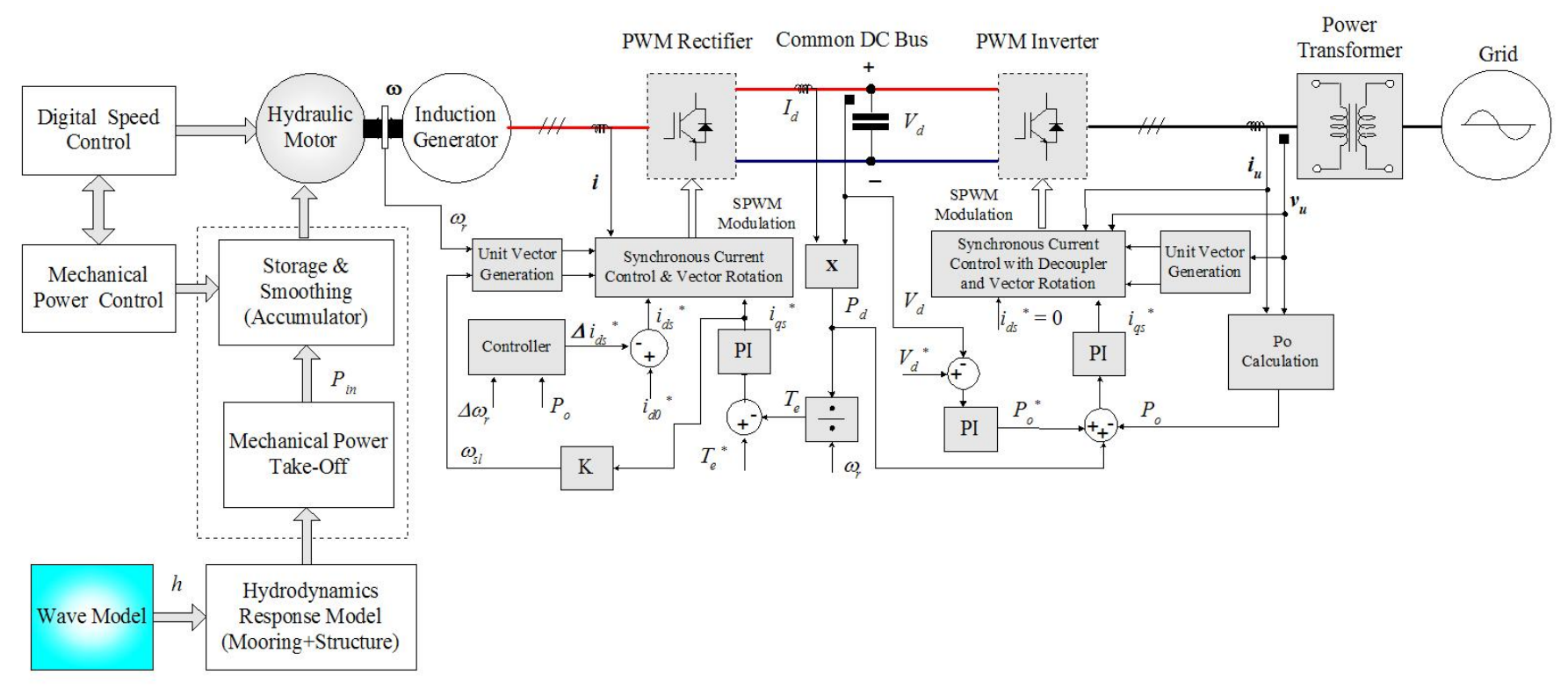

Fig. 2. Generalized electrical and power take-off modelling for wave energy system.

\section{POWER TAKE-OFF MECHANISMS}

Wave energy companies have been actively involved in the development of new wave energy schemes such as the Oscillating Water Column (OWC), the Pelamis, the Wave Point Absorbers and the Wave Dragon. The main components of a WEC system are illustrated in Fig. 2, including the mechanical power take-off, accumulator, hydraulic motor, generator, transformer, and potential power electronics. The power take-off mechanisms are a mixture of hydraulic motors, aero-turbines and direct-drive linear generators as given in Table1. The power take-off system converts the captured mechanical energy into electrical energy. The power takeoff depends on the method of energy capture employed in the device. In an Oscillating Water Column, an air turbine is used. In an offshore floating wave device with working surfaces moving at velocities in the region of $1 \mathrm{~m} / \mathrm{s}$, highpressure oil hydraulics offer the best solution due to their high energy density and the possibility of on-board energy storage for smoother delivery. The Pelamis has hydraulic rams which pump high-pressure oil through hydraulic motors via smoothing accumulators. A mechanical interface is employed to convert the slow-speed rotation or reciprocating motion into high-speed rotational motion for connection to a conventional rotary electrical generator, such as an induction machine.

TABLE I

POWER TAKE-OFFS AND GENERATORS [4]-[9]

\begin{tabular}{|c|c|c|c|}
\hline Device & Power take-off & Generator & Speed \\
\hline Pelamis & Hydraulics & Induction & Fixed \\
\hline $\begin{array}{c}\text { Archimedes } \\
\text { wave swing }\end{array}$ & $\begin{array}{c}\text { Direct-drive linear } \\
\text { generator }\end{array}$ & $\begin{array}{c}\text { Linear permanent } \\
\text { magnet }\end{array}$ & Variable \\
\hline $\begin{array}{c}\text { Wave } \\
\text { Dragon }\end{array}$ & Water turbine & $\begin{array}{c}\text { Rotary permanent } \\
\text { magnet }\end{array}$ & Variable \\
\hline Oceanlinx & $\begin{array}{c}\text { OWC and variable } \\
\text { pitch turbine }\end{array}$ & Induction & Variable \\
\hline
\end{tabular}

\section{GRID INTEGRATION OF A VARIABLE SPEED WEC}

In Fig. 2, the grid integration of the Oscillating Water Column (OWC) or the Wave Dragon uses full-scale power electronics. A power electronics interface provides excellent controllable characteristics for these devices.

The generator speed is controlled by indirect vector control, with synchronous current and torque control in the inner loops. In order to enhance the generator efficiency, the generator rotor flux is controlled in an open loop by control of the $i_{d s}$ current. The rectifier converts the variable-frequency variable-voltage power generated by the induction generator to DC power. The DC power is inverted to a $50 \mathrm{~Hz}$ fixed $\mathrm{AC}$ voltage through a grid-side inverter. The DC-link voltage controller regulates the line power $P_{o}$ so that the DC-link voltage always remains constant. A feed-forward power signal from the induction generator output to the DC voltage loop prevents transient fluctuations in the DC-link voltage.

The grid-side inverter is also vector-controlled using direct vector control and synchronous current control in the inner loops. The output power $P_{o}$ is controlled to control the DClink voltage $V_{d}$. Since an increase in $P_{o}$ causes a decrease in $V_{d}$, the voltage loop error polarity has been inverted. The inverter enables fast control of the active and reactive powers, which have a significant impact on the grid integration system. It also reduces the harmonic currents in order to keep the harmonic voltages within acceptable limits and meet the grid code requirements.

For the Wave Dragon device, which employs a permanent magnet synchronous generator, the PWM rectifier can be replaced by a rectifier to boost the converter and achieve the same level of control. 


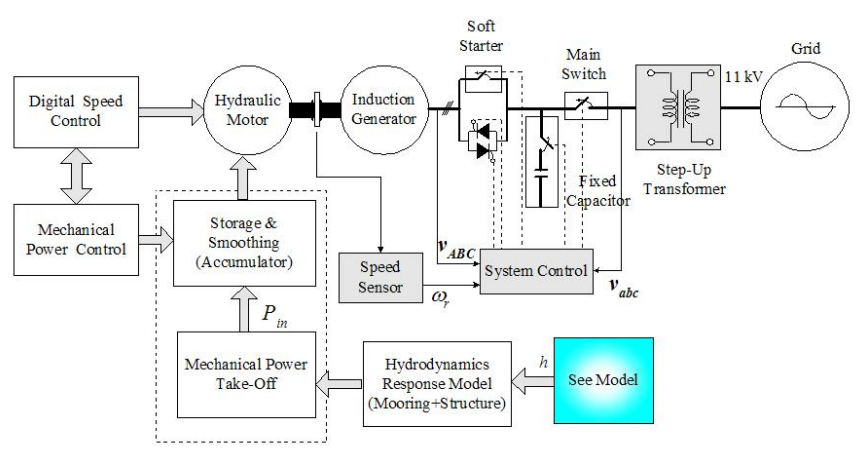

Fig. 3. Schematic configuration of directly connected induction generator-wave power generation system.

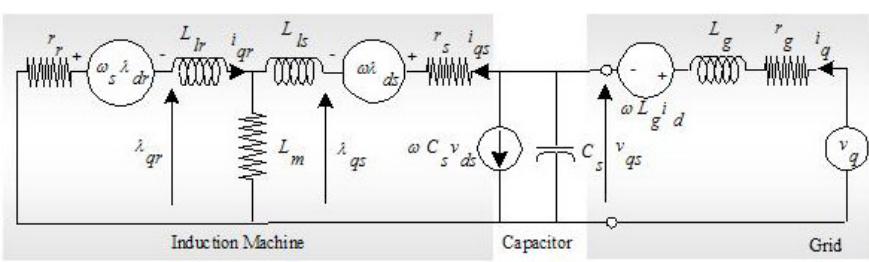

(a) q-axis

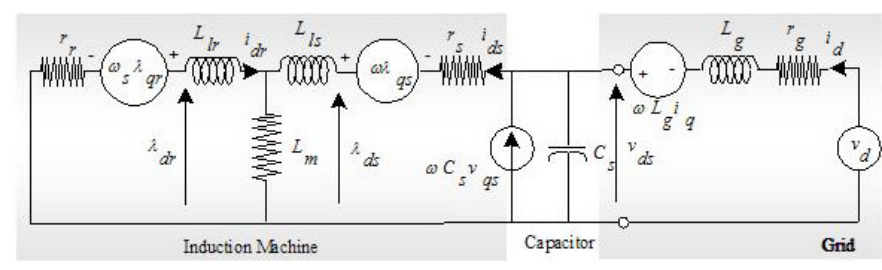

(b) d-axis

Fig. 4. Simplified induction-generator directly connected to the Grid.

\section{POWER GRID INTEGRATION OF THE PELAMIS}

The negative side of a variable speed wave devices is a complex grid-integrated system where sensitive power electronic parts are required. In addition, the cost of the power converter will be high especially for the Pelamis device, which utilizes six generators each rated at $125 \mathrm{~kW}$. The Pelamis device uses a squirrel-cage induction generator directly connected to the grid. Therefore, this wave device must operate at a constant speed of $1500 \mathrm{rpm}$ with an allowable variation of $1-2 \%$. It adjusts the rotor speed by controlling the hydraulic motor, which drives the induction generator to produce electricity. The $50 \mathrm{~Hz}, 415 \mathrm{~V}$ output voltage of the generator is low. Therefore, there will be a 950kVA step-up transformer on the device. The induction machine requires local power-factor correction (PFC) usually in the form of mechanically switched capacitors. The PFC may be a thyristor switched capacitor or it might even be dynamic although these typically have a higher failure rate. The WEC reactive control is likely to be very coarse unless a continuous method of dynamic PFC has been installed. In addition, the induction machine generally requires a soft-starter to reduce the inrush current during start-up. Fig. 3 shows the basic configuration of this design.

\section{A. $d-q$ axis Equivalent-Circuit of the Pelamis}

Fig. 4 shows the $d-q$ axis equivalent-circuit of an IG system consisting of a conventional three phase squirrel cage induc- tion machine (IM). The IM stator is connected to the grid and to a capacitor bank. The capacitor bank provides the reactive current needed to excite the IM and it acts as an uncontrolled reactive current source that provides the required excitation.

Where, the subscripts $s, r$ and $g$ denote stator, rotor and grid quantities, respectively. $i_{q s}, i_{d s}, v_{q s}$ and $v_{d s}$ are the $d-q$ axis induction machine stator currents and voltages. $i_{q}, i_{d}, v_{q}$ and $v_{d}$ are the $d-q$ axis grid currents and voltages. $r_{s}$ and $r_{r}$ are the stator and rotor resistances, respectively. $L_{m}$ is called the magnetizing inductance. $L_{l s}$ and $L_{l r}$ are the stator and the rotor leakage inductances, respectively. $\omega_{s}\left(\omega_{s}=\omega-\omega_{r}\right)$ is the slip frequency which is the frequency of the actual rotor current. $\omega$ and $\omega_{r}$ are the angular speeds of the arbitrary reference frame and the rotor, respectively.

\section{B. Capacitor Design for the Pelamis}

The capacitor-bank is installed to supply the induction machine with the required reactive current where the grid reactive current $\left(i_{d}\right)$ can be minimized in order to reduce the grid rms current and the transmission losses. It can be installed with small units connected in parallel in order to avoid any excessive capacitor-bank reactive current which will be the main reason for increasing the value of the utility rms current. In order to select the value of the capacitor bank $\left(C_{s}\right)$, a simple and useful rotating reference frame is chosen to align the stator voltage vector $v_{s}$ of the IM on the quadrature axis. Using this $d-q$ reference frame, the direct and quadrature voltage components are: $v_{d s}=0$ and $v_{q s}=\left|v_{s}\right|$ respectively. Then the instantaneous active and reactive powers are defined by:

$$
\begin{aligned}
p & =\frac{3}{2} v_{q s} i_{q s} \\
q & =-\frac{3}{2} v_{q s} i_{d s} .
\end{aligned}
$$

The $d$-axis and $q$-axis current components are the active and reactive power products, respectively. The power factor is defined as follows:

$$
p f=\frac{i_{q s}}{\sqrt{i_{q s}^{2}+i_{d s}^{2}}} .
$$

Fig. 5 shows the measured transient response of a $2.5 \mathrm{~kW}$ induction generator, when the rotor speed changes with a variation of 1-3.3\% above the synchronous speed. The active current $\left(i_{q s}\right)$ has a positive effect on the power factor in that a more active current output results in a higher power factor. The power factor of the induction generator is almost a constant 0.87 at a higher $i_{q s}$.

Since a capacitor bank has been selected to provide the whole stator reactive current at 1 pu voltage, the grid reactive current is near to null. Under these conditions, the stator reactive current becomes:

$$
i_{d s}=\omega C_{s} v_{q s} .
$$

From the above equation, the stator reactive current $\left(i_{d s}\right)$ depends on $v_{q s}$. The main drawback to this is that the IM 


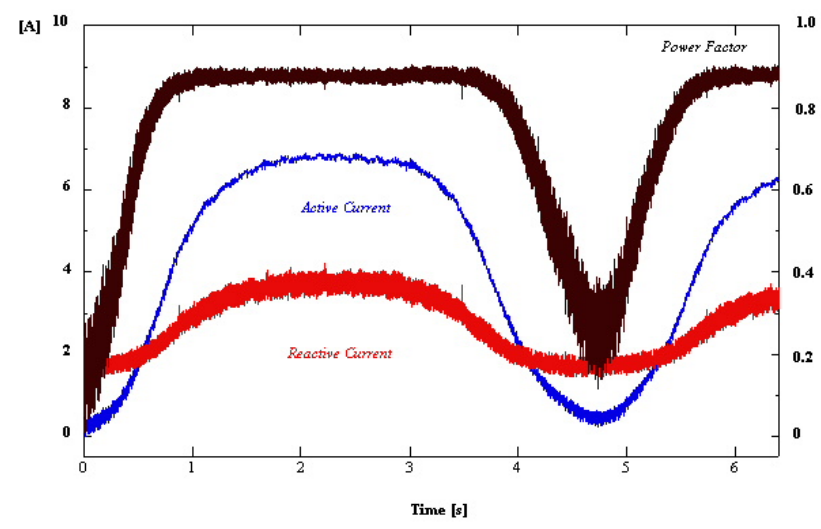

Fig. 5. Measured transient response of the fixed-speed type induction generator.

efficiency may be very low because it works in the saturation region. The stator voltage is defined as follows:

$$
v_{q s}=\omega \phi_{m}\left(i_{d s}\right)
$$

$\phi_{m}\left(i_{d s}\right)$ is simply approximated by a straight-line tangent to the magnetizing curve at the operating point $\left(L_{m s a t}\right.$ at the rated $i_{q s}$ ) which is represented by:

$$
\phi_{m}\left(i_{d s}\right)=k+L_{m s a t} i_{d s} .
$$

Then, the generated voltage is simply expressed by:

$$
v_{q s}=\frac{\omega k}{1-\omega^{2} L_{m s a t} C_{s}} .
$$

The quadrature stator voltage $\left(v_{q s}\right)$ must stay within acceptable limits by selecting a suitable capacitor bank in order to avoid the saturation of the induction machine that may occur due to an excessive reactive current. Solving the above equation, the capacitance $C_{s}$ can be expressed by:

$$
C_{s}=\frac{1}{\omega^{2} L_{m s a t}}-\frac{k}{\omega L_{m s a t} v_{q s}} .
$$

\section{RESULTS AND DISCUSSIONS}

\section{A. Effect of the WEC Speed}

Fig. 6 shows the mechanical speed response of the direct connection of the fixed speed WEC known as the Pelamis in pu (base 1500rpm), the WEC active power response in MW, the WEC reactive power response in MVAr and the WEC power factor response respectively, under variable mechanical power of the hydraulic system of the WEC device. The active power output from the WEC is linearly proportional to the mechanical speed variation which is kept within $2 \%$ of the synchronously rated speed of the generator, using an accumulator for smoothing and storage. The active power has a positive effect on the power factor in that more active power output results in a higher power factor. In addition, the variation range of the reactive power is not great compared
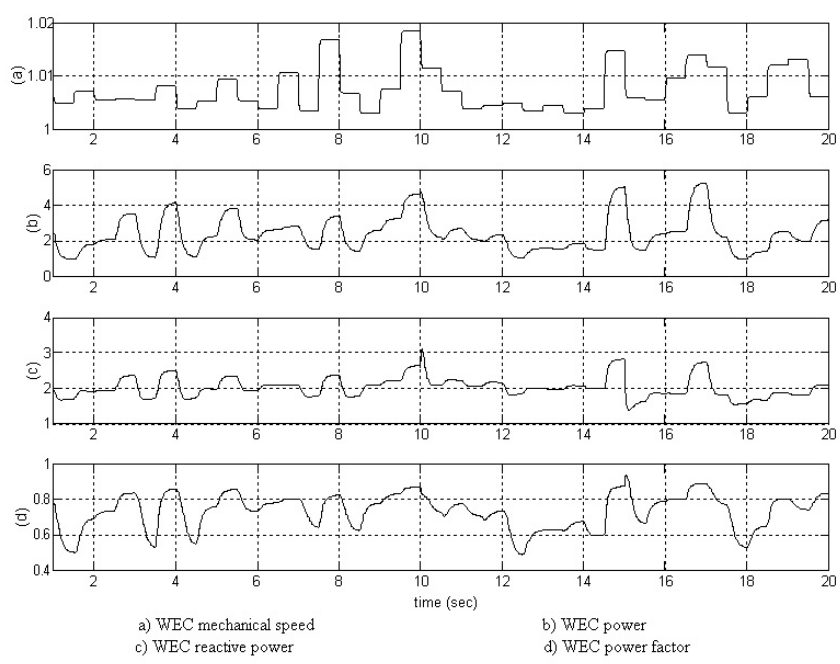

Fig. 6. Operating performance of the direct connection of the fixed speed WEC under variable mechanical power or speed.
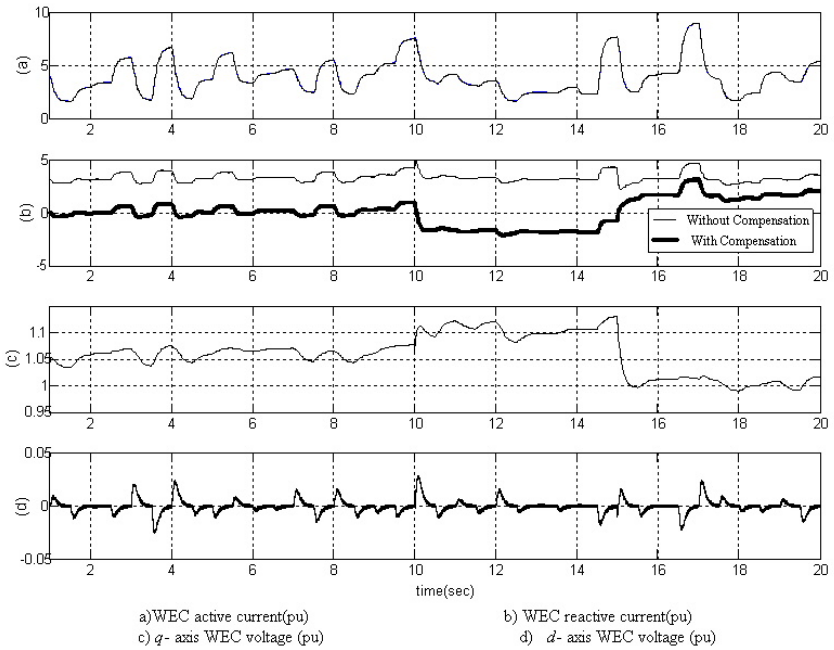

Fig. 7. Voltage and current of the direct connection of the fixed speed WEC under variable mechanical power in $d-q$ axis reference frame.

with the range of the active power variation. Therefore, a fixed capacitor is able to compensate the required reactive power of the WEC and then control the WEC power factor.

Fig. 7 shows the $d-q$ axis current and voltage components of the WEC respectively, under the condition of variable mechanical power output from the hydraulic system of the WEC device. The active current component has a significant effect on the WEC voltage. Higher values of active current will raise the voltage level above the rated voltage. However, the reactive current, which mainly causes a lower power factor, especially with lower values of active current, can be significantly decreased using a reactive power compensation unit. The reactive power control of a WEC has a significant impact on the voltage level of the WEC. At unity or a lagging power factor, reactive power control is able to keep the voltage level within its limits. However, the voltage level goes above the voltage limit $( \pm 10 \%)$ with a capacitive power factor. 

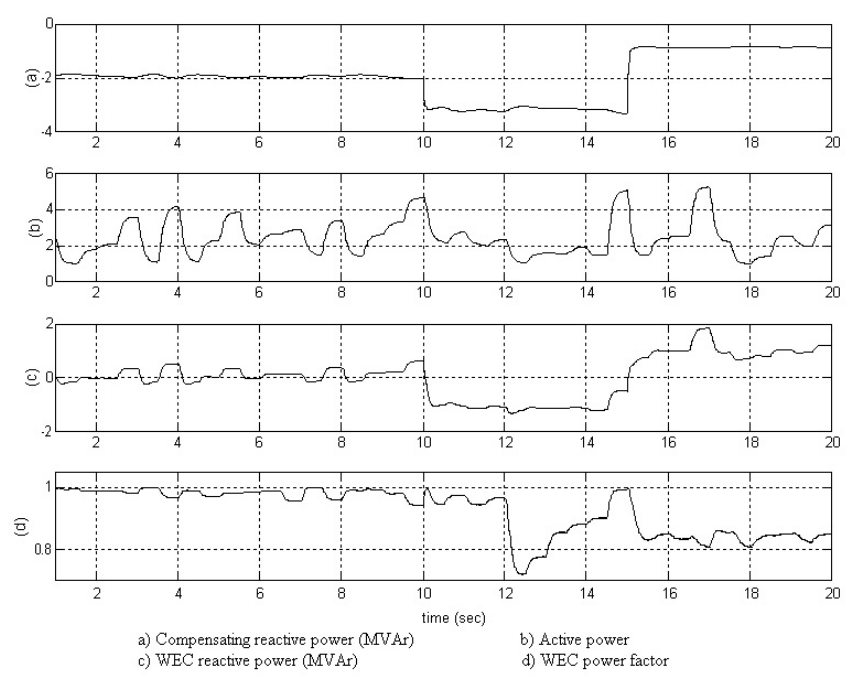

Fig. 8. Effect of reactive power compensation on the fixed speed WEC under variable mechanical power.

\section{B. Effect of Reactive Power Control}

In order to control the reactive power of the WEC within its limits, the offshore reactive power control, based on the reactive power compensation unit installed near the WEC device, is utilized. The offshore reactive power compensation unit can be installed to absorb or generate reactive power and hence to control the power factor of the WEC device. As can be seen in Fig. 8, the reactive power compensation unit has reduced the reactive power almost to its lowest value, i.e. the effect of the reactive power is negligible during the first 10 sec. Between $10 \mathrm{sec}$ and $15 \mathrm{sec}$, the compensation unit shows its ability to supply the required reactive power to the grid. However, it absorbs the desired reactive power within the last $5 \mathrm{sec}$.

Fig. 9 shows the WEC reactive power in MVAr, the WEC active power in MW, the rms current of WEC in pu (base, 1004amps) and the WEC voltage in pu (base, 575volts) respectively, with or without the reactive power compensation unit. At unity power factor, the WEC current drops to its lowest value which is equal to the active current. However, the WEC voltage rises $6 \%$ to $8 \%$ above the rated voltage. With the reactive power compensation unit, the rms current of the WEC is decreased to be approximately equal to the active current component, i.e. the reactive current becomes negligible when a well-designed fixed capacitor bank is connected. It is clearly shown that the reactive power supplied from or to the utility as shown in (a) is negligible during the first $10 \mathrm{sec}$. The reactive power compensation using the fixed capacitor bank provides a unity power factor and reduces the grid currents by about $15 \%$ to $20 \%$. This will improve the system efficiency to $95 \%$ by decreasing the cables losses. However, the voltage level of the WEC exceeds the rated voltage while remaining within its acceptable limits (10\%).

Fig. 10 indicates that the WEC has a highly variable power output even with energy smoothing and storage between the hydraulic system and the electric motor, which keeps the
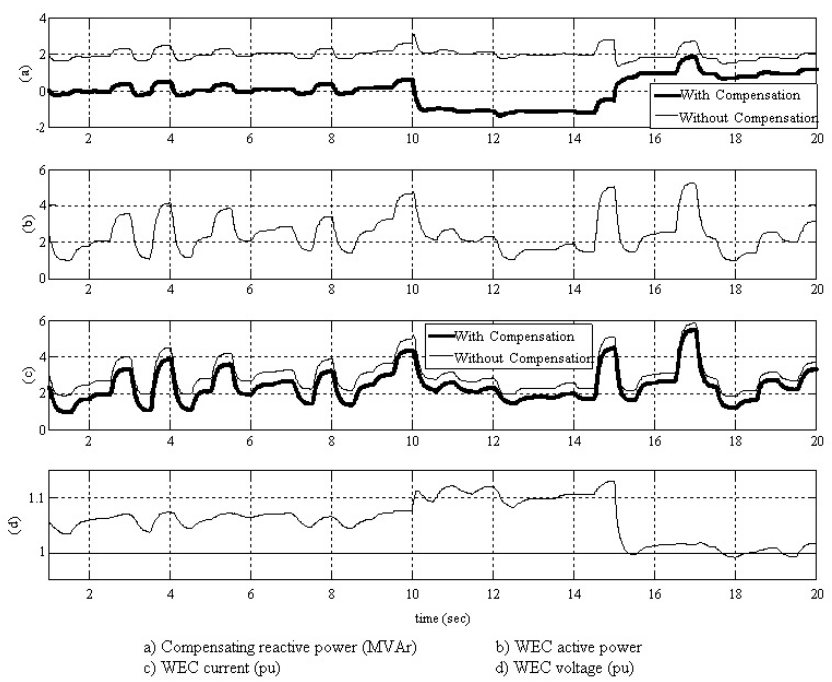

Fig. 9. Effect of reactive power compensation on the WEC current and voltage under variable mechanical power.
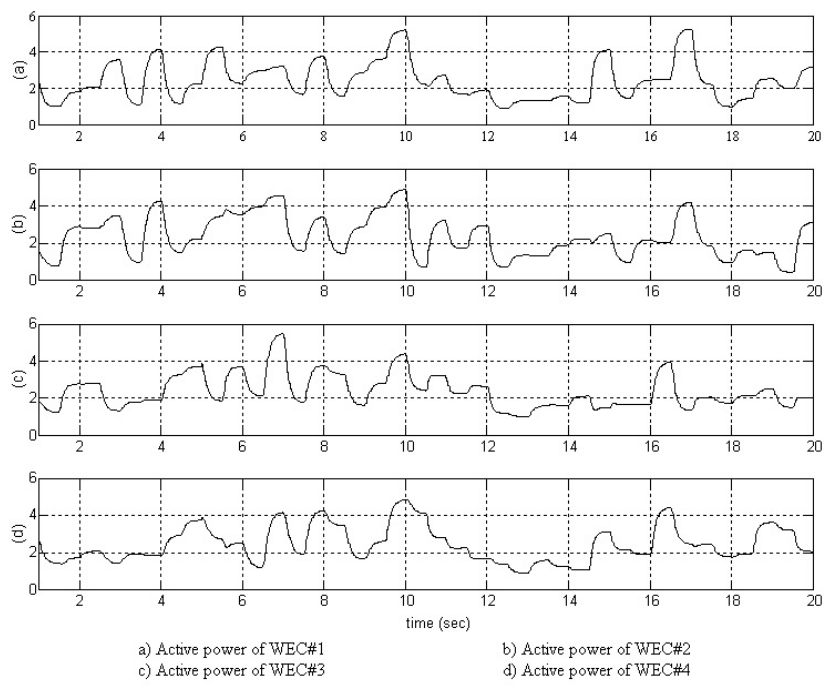

Fig. 10. Active power of multi WECs with different output characteristics.

mechanical speed above the synchronous speed of the electric generator using a digital electronic control. The instantaneous power output goes from zero to maximum output within seconds with a power variation of 1 to $5 \mathrm{MW}$. It is expected that without any means of energy storage for a single WEC, the power output variation can be quite large.

\section{Power Quality of the Wave Power Plant}

For several WEC devices connected together in a wave farm with different output characteristics, Fig. 11 shows that the grid power variation is reduced. However, it may still be a challenge to power quality for a higher penetration of the wave energy. The response of the grid power to the four typical WECs is an increase in the average power and a reduction in the grid power fluctuations, indicating greater smoothing due to greater output diversity across the site. The reactive power variations 

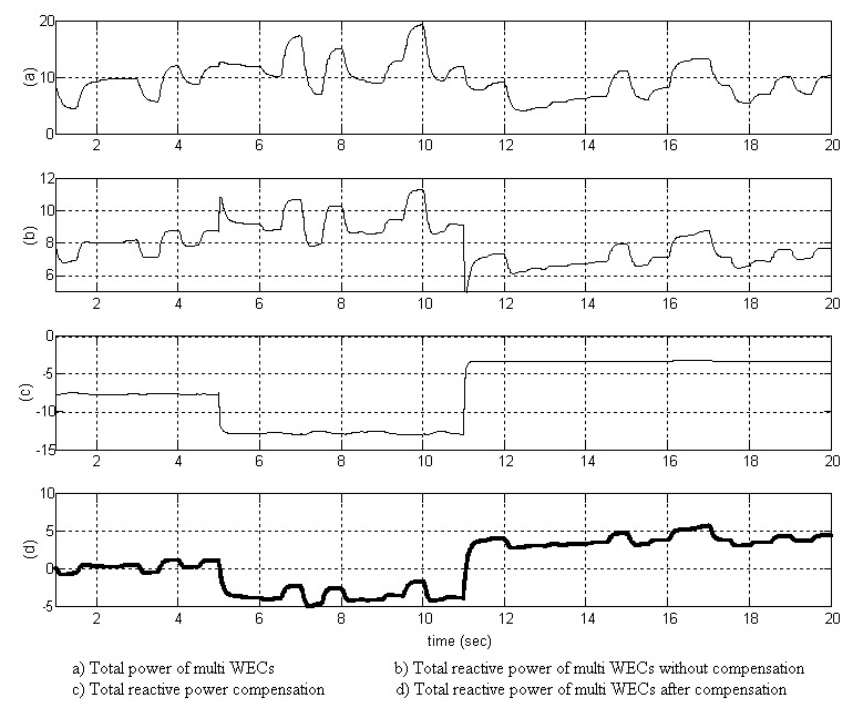

Fig. 11. Reactive power compensation of multi WECs.
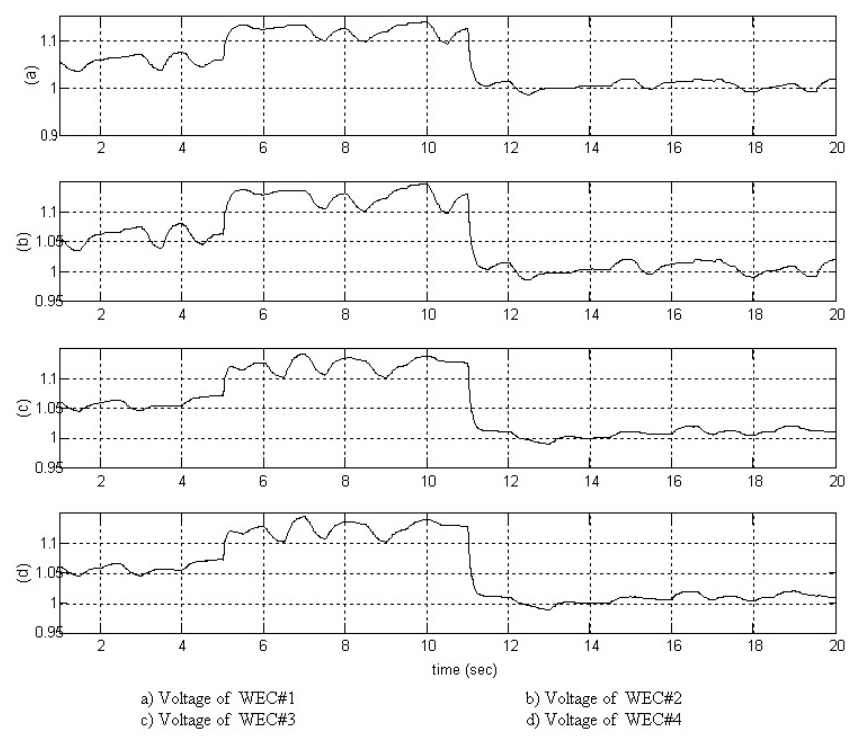

Fig. 12. Voltage fluctuations at the terminals of each WEC device.

in the four typical WECs and the grid with reactive power compensation for each WEC unit indicate that, without WEC power factor control or reactive power compensation, higher reactive power variation is absorbed or generated from the grid. Peak reactive power is reduced for the array of WEC devices due to reactive power compensation.

Fig. 12 shows the voltage variations at the terminals of the four WECs. During the first five seconds, the switched capacitor is connected to each WEC unit in order to render a power factor close to unity. The unity power factor causes a rise in the terminal voltage. The voltage rise is approximately $6 \%$ to $8 \%$ at peak power output, based on an $11 \mathrm{kV}$ substation being maintained at $1.0 \mathrm{pu}$. From eleven to twenty seconds, the WECs operate at a lagging power factor which causes a reduction in the WEC terminal voltage while the terminal
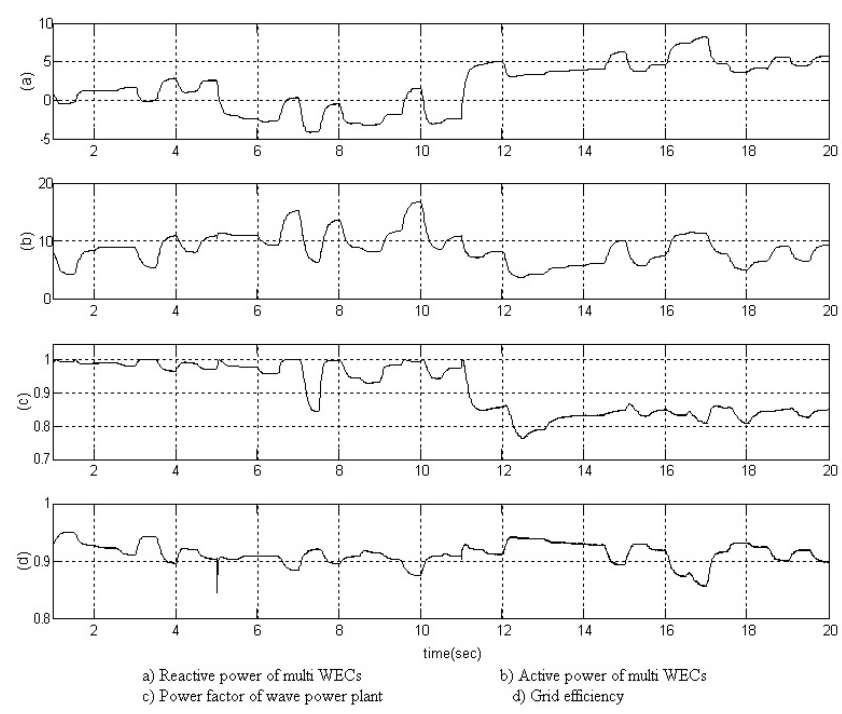

Fig. 13. Grid efficiency and power factor of wave power plant based on $16 \mathrm{MW}$ installed capacity.

voltage exceeds the voltage level from five to eleven seconds at a leading power factor.

Fig. 13 shows the grid efficiency and power factor of the wave power plant with reactive power compensation. When the WECs are operating at approximately unity power factor, it is possible to achieve high performance for between one and five seconds.

The reactive power compensation unit significantly improves the wave power plant efficiency (up to 96\%) by reducing the cable losses.

The power output analysis has shown that it is possible to expect a $50 \%$ power variation within time-frames on the order of 10 seconds. This will result in a maximum voltage fluctuation of $12 \%$ at the WEC array interface. This is likely to be achievable for WECs in terms of an operating environment.

Allowing the WECs to generate at an inductive power factor minimizes the voltage range at the WEC terminals and reduces the transformer tap range required. However, it also increases the onshore required reactive power compensation. With dynamic reactive power control, the power-factor can be controlled to between 0.95 lagging and unity. This maximizes the voltage range at the WEC terminals and increase the transformer tap range required, but reduces the required onshore reactive power compensation. A variety of options for wave power plant operation that maintain the voltage tolerances and reactive power flows within its limits include:

1) The provision of a $33 / 11 \mathrm{kV}$ transformer with a tap changer having a range of $\pm 10 \%$.

2) Operating the WEC generation at unity power factor.

3) The provision of a 6MVAr switched capacitor bank compensator.

4) Using larger WEC connecting cables.

\section{CONCLUSIONS}

The wave power plant is made up of an array of multi wave energy converters connected to a distribution grid on the 
local shore is presented. In this scheme, the power generated from four wave energy conversion units based on designs from different wave energy developers is fed through a 6-core $33 \mathrm{kV}$ cable initially operated as two independent circuits at $11 \mathrm{kV}$ with each circuit connecting two WEC units. Operating the cable at $11 \mathrm{kV}$ on both circuits provides a maximum capacity of $16 \mathrm{MW}$ split equally across the cables with wave energy devices operating at a constant lagging power-factor of 0.98 and the substation $11 \mathrm{kV}$ voltage at 1.0 per-unit. A combination of electrical generation systems for the power take-off of WEC devices, including directly connected generation devices (asynchronous) as well as $\mathrm{dc} / \mathrm{dc}$ converters and inverters, are used to integrate all wave power to the grid. Suitable control of the inverters is suggested to ascertain satisfactory performance of the proposed scheme under different operating environments. The performance of the proposed scheme is demonstrated in detail through MATLAB/SIMULINK simulations. The simulation results show the effect of the wave energy array power-factor on the voltage rise and reactive power compensation requirements. It also presents the effect on system efficiency or the cable losses to meet the good transient performance of the proposed system under different types of power fluctuations.

\section{REFERENCES}

[1] N. Mohan, T. M. Undeland, and W. P. Robbins, Power Electronics: Converters, Applications and Design, New York: Wiley, 1989.

[2] M. Leijon et al., "Multiphysics simulation of wave energy to electric energy conversion by permanent magnet linear generator," IEEE Trans.Energy Conversion, Vol.20, No.1, pp. 219-224, Mar. 2005.

[3] J. Falnes, Ocean Waves and Oscillating Systems: Linear Interaction Including Wave Energy Extraction, Cambridge, U.K.: Cambridge Univ. Press, 2002.

[4] S. S. Y. Narayanan, B. K. Murthy, and G. S. Rao, "Dynamic analysis of grid-connected induction generator driven by a wave-energy turbine through hunting network," IEEE Trans. Energy Conversion, Vol.14, No.1, pp. 115-120, Mar. 1999.

[5] Biswarup Das, and Bikash C. Pal, "Voltage control performance of AWS connected for grid operation," IEEE Trans. on Energy Conversion, Vol.21, No.2, Jun. 2006.
[6] D. Ravi Kiran, A. Palani, S. Muthukumar, and V. Jayashankar "Steady grid power from wave energy," IEEE Trans. on Energy Conversion, Vol.22, No.2, pp.539-540, Jun. 2007.

[7] Feng Wu, Xiao-Ping Zhang, Ping Ju, and Michael J. H. Sterling, "Modeling and control of AWS-based wave energy conversion system integrated into power grid," IEEE Trans. on Power Systems, Vol.23, No.3, pp.1196 - 1204, Aug. 2008.

[8] Rothenhagen, K. Jasinski, M. Kazmierkowski, M.P. “Grid connection of multi-megawatt clean wave energy power plant under weak grid condition," Power Electronics and Motion Control Conference, EPEPEMC 2008, pp. 1904 - 19, Sep. 2008.

[9] M. Molinas, O. Skjervheim, P. Andreasen, T. Undeland, J. Hals, T. Moan,and B. Sorby, "Power electronics as grid interface for actively controlled wave energy converters," IEEE International Conference on Clean Electrical Power, ICCEP '07, pp.188-195, 2007.

[10] M. H. J. Bollen and A. Sannino, "Voltage control with inverter based distributed generation," IEEE Trans. Power Del., Vol.20, No.1, pp. 519520, Jan. 2005.

[11] M. E. Baran and F. F.Wu, "Network reconfiguration in distribution systems for loss reduction and load balancing," IEEE Trans. Power Del., Vol.4, No.2, pp. 1401-1407, Apr. 1989.

[12] P. Karlsson and J. Svensson, "DC bus voltage control for a distributed power system," IEEE Trans. Power Electron., Vol.18, No.6, pp. 14051412, Nov. 2003.

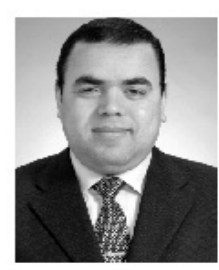

Tarek Ahmed received his Ph.D. in Electrical Engineering from Yamaguchi University, Japan in 2006. Since 2009, he has been conducting research within the Renewable Energy Research Group at the University of Exeter in the area of wave energy development to create a major grid-connected project off the north coast of Cornwall, UK. In addition, he is a Lecturer in the Electrical Engineering Department, Faculty of Engineering, Assiut University, Assiut, Egypt. Dr. Ahmed joined the Assiut Engineering faculty in 1995, as an Instructor. In 1998, on completion of his master's degree, he was made a Teaching Assistant in the Department of Electrical Power \& Machines within the same department. His research interests include power electronics and electric machine control for grid integration of renewable energy. Dr. Ahmed has received the best paper awards from the Institute of Electrical Engineers of Japan in 2003, 2004, and 2005. $\mathrm{He}$ has also received the best paper and student awards from the 30th Annual Conference of the IEEE Industrial Electronics Society, 2004, the best paper award from the International Conference on Electrical Machines and Systems, 2004 and the best paper award from the 8th IEEE International Conference on Power Electronics and Drive Systems, 2009. Dr. Ahmed is a member of the Institute of Electrical and Electronic Engineers and has been widely published in many international journals. 